\title{
Influence of Traffic Load and Far-Field Seismic Excitation in Cables of Cable-Stayed Bridge
}

\author{
Nor Ashikin Muhamad Khairussaleh, Lee Chong Hoe, G.A.R. Parke, Roslina Omar, Shariza Mat \\ Aris
}

\begin{abstract}
Bridges are always expose to the cyclic live loads in the form of moving traffic and wind loads. This could jeopardise the service life of the bridges peculiarly in fatigue. With the rise of seismic activities nowadays, bridges may become more susceptible to fatigue damage. Thus, in this study, the static and dynamic behaviour of a cable-stayed bridge in terms of fatigue of steel elements are addressed by focusing on the stress variation in stay cables due to the effects of moving traffic loads and ground motion excitations. Fatigue Load Model 4 (FLM 4) has been adopted as a dynamic response on the bridge subjected to moving load while a two set of ground motions considering horizontal and vertical motions from far-field faults has been used as seismic excitation on the bridge. The results of this study revealed the notable influence of traffic loads on stress variations of cable-stayed bridges with significant effects due to ground motions scaled to the expected return period.
\end{abstract}

Keywords : Cable anchorages, cable-stayed bridge, FLM 4, Far-field ground motion.

\section{INTRODUCTION}

Cables are one of the important elements in the cable-stayed bridge as it holds the stiffness of the bridge by anchoring to the deck. However, fatigue phenomena become a potential threat to the premature of the service life of cable-stayed bridge since stay cables are subjected to high tensile forces and high-stress variation due to the variation load such as traffic, wind and seismic. Moreover, fretting fatigue could occur if the inter-wires have a contact surface for a certain period excessively. According to $\mathrm{Yan} \mathrm{Li}$ et al. (2011), most existing studies on the fatigue of cable-stayed bridges only consider traffic and/or wind load. However, the increase in the occurrence of seismic activities in the region of South East Asia has the potential to increase the exposure of steel structures towards cyclic loads since ground motions have the same attributes as pulsating loads. This will eventually lead to the reduction in fatigue life of cable anchorages along with corrosive damage. In this study, the analysis of stress variations of a cable-stayed bridge is

Revised Manuscript Received on October 22, 2019.

* Correspondence Author

Nor Ashikin Muhamad Khairussaleh*, Faculty of Civil Engineering Technology, Universiti Malaysia Pahang (UMP), Lebuhraya Tun Razak, Gambang, 26300, Malaysia. Email: aasyiq@ump.edu.my

Second Author Name, Faculty of Civil Engineering Technology, Universiti Malaysia Pahang (UMP), Lebuhraya Tun Razak, Gambang, 26300, Malaysia. Email:chonghoe6@gmail.com

Third Author Name, Faculty of Engineering and Physical Sciences, Department of Civil and Environmental Engineering, University of Surrey, Guildford, Surrey GU2 7XH, United Kingdom. Email: g.parke@surrey.ac.uk addressed by modelling the $475 \mathrm{~m}$ Penang Second Bridge by inducing traffic and seismic loads and comparing their effects on stress range of cables. This paper takes consideration into the combined actions of traffic and seismic loads on a cable-stayed bridge that could further affect the fatigue life of stay cables.

\section{METHODS}

The $475 \mathrm{~m}$ Second Penang Bridge was modelling in SAP2000 software. The detail specification of the bridge mainly was taken online from Jambatan Kedua Pulau Pinang Sdn Bhd. and AECOM. The Second Penang Bridge is the second dual-plane cable-stayed bridge in Malaysia that links Penang Island to mainland Batu Kawan. It is a two-pylon, three-span prestressed concrete cable-stayed bridge which consists of two - pairs of towers with the main span and side spans of $240 \mathrm{~m}$ and $117.5 \mathrm{~m}$ respectively. The cables are arranged in four vertical planes, each with 18 cables on both sides.

\section{A. Modelling The Second Penang Bridge in SAP2000}

A three-dimensional finite element model of the Second Penang Bridge was developed in the SAP2000 in order to depict a more exact value of stress in cables as shown in Fig 1. The main structural elements (stay cables, concrete pylons and concrete deck girders) were discretized by several element types in the model. The stay cables were modelled as straight frame cable elements in SAP2000 representing the final condition of the bridge's construction stage. In order to present the pretension force in the cable, the initial strain was applied to each cable. The value of the initial strain can be adapted by using Hooke's Law. However, in order to achieve its nonlinear behaviour, the equivalent tangential modulus method is applied with the equivalent tangential modulus of elasticity Eeq by Ernst (Alfredo Camara Casado, 2011).

$$
E_{e q}=\frac{E_{p}}{1+\frac{w_{p}^{2} d_{p}^{2} E_{p} A_{T}}{12 F_{P_{d} 0}^{\mathrm{d}}}}
$$

Where $E_{p}$ is the initial modulus elasticity of cables, wp is the unit weight of stay cable, $d_{p}$ is the horizontal projection of stay, $\mathrm{A}_{\mathrm{T}}$ is the cross-sectional area, and $\mathrm{F}_{\mathrm{p}, 0}$ is the initial prestress force of the cable. Since the concrete pylons have a varying cross-section, thus it was modelled with non-prismatic frame elements in SAP2000 whereas the deck was modelled with frame elements. 


\section{B. Traffic Loading}

Based on BS EN 1991-2, there are five different types of fatigue load model 1 (FLM 1) to fatigue load model 5 (FLM 5). However, only FLM 4 and FLM 5 considered the fatigue-loading condition with the influence of stress generated during cyclic loading. In addition to this, FLM 5 is considered the most accurate basis for pretending fatigue life, yet it should be based on the actual traffic flow of the traffic volume on the bridge. Therefore, in this study, FLM 4 was used comprises of five sets of standard lorries recommended in the Eurocode (BS EN 1991-2, 2004). In addition, a constant velocity of $80 \mathrm{~km} / \mathrm{hr}$ was set to each lorry in crossing the bridges as this speed limit in stated in the Malaysia Motor Vehicles Rules 1989.

\section{Ground Motion Data}

By using the NGA West 2 strong motion database taken
From the Pacific Earthquake Engineering Research (PEER) Center, the effect of ground motion was analysed on the Second Penang Bridge model. The data used taken are based on the fixed range of characteristics in terms of maximum peak ground acceleration (PGA) of $0.109 \mathrm{~g}$ with a return period of 2500 years, fault types, epicentral distances and magnitude of quake event (Man et al., 2018). In addition, the epicentral distance of at least $250 \mathrm{~km}$ from the site of interest was taken to determine the PGA values applied to the Second Penang Bridge. Thus, two locations, namely Kocaeli and Denali have been identified to be a potentially suitable tremor that could be detected at Malaysia based on the mapping for South East Asia from the United States Geological Survey (USGS). With consideration of both horizontal and vertical motions of the tremor, a set of linear direct integration time history analysis has been carried in SAP2000. Tab I shows a detail of the ground motion selected for this study.
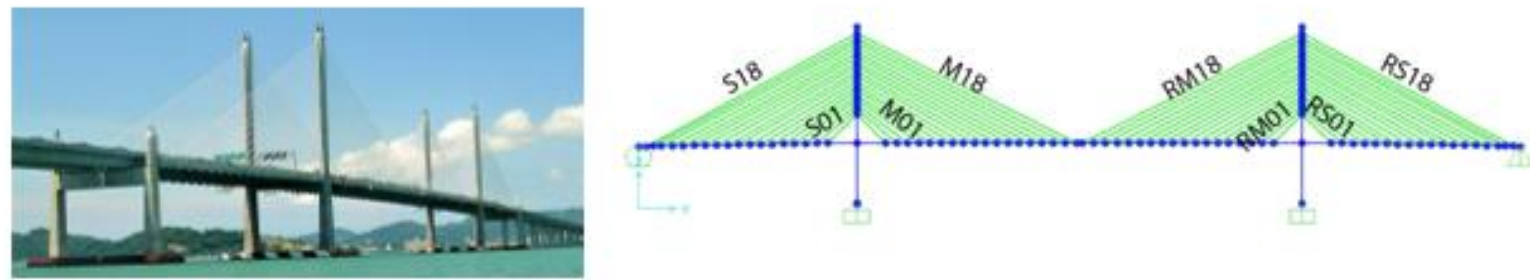

Fig 1. Photograph of the Second Penang Bridge (left) and Finite element model of Cable-Stayed Bridge

Table 1: Ground motion selected for the analysis

\begin{tabular}{|c|c|c|c|c|c|c|c|}
\hline No. & Earthquake & Station & Mw & $\begin{array}{c}\text { Fault } \\
\text { Mechanics }\end{array}$ & $\begin{array}{c}\text { Epicentral } \\
\text { Distance (km) }\end{array}$ & $\begin{array}{c}\text { Spectral PGA (g), } \\
5 \% \text { damping }\end{array}$ & $\begin{array}{c}\text { Scale } \\
\text { Factor }\end{array}$ \\
\hline 1 & $\begin{array}{c}\text { Kocaeli, Turkey } \\
(2002)\end{array}$ & Bornova & 7.51 & $\begin{array}{c}\text { Reverse }+ \\
\text { Strike-Slip }\end{array}$ & 315.89 & 0.03 & 3.633 \\
\hline 2 & Denali, Alaska & $\begin{array}{c}\text { Anchorage }- \\
\text { DOI Off. Of } \\
\text { Aircraft }\end{array}$ & 7.9 & $\begin{array}{c}\text { Reverse }+ \\
\text { Strike-Slip }\end{array}$ & 272.50 & 0.04 & 2.725 \\
\hline
\end{tabular}

\section{RESULTS AND DISCUSSIONS}

The results of this study have shown the influenced of the moving traffic and the ground motion as discussed below.

\section{A. Influence by Moving Traffic}

Based on FLM 4, two forms of traffic configuration namely both a single and convoy lorries should be used to determine stresses occurring in stay cables. Fig. 2 shows the plot function of applied force in stay cables at the left side span (LS01) when the lorry was set to transit alone along the bridge. It shows that cable LS01 experienced the highest axial force when the third lorry (FLM4-C) was crossing the bridge. Fig. 3 shows the nominal stress occurring in the cables on the Second Penang Bridge resulting from the passage of single lorry. With this reaction, the stress ranges in the cables can be determined as shown in Fig. 4. This figure illustrates that the stress ranges are found to be highest in the stay cable nearer to the pylon and decreasing towards the mid-span. However, the stress ranges show that it is increasing in the stay cables further from the pylon but nearer to the support reaction.

Nearly the same pattern of stress ranges in the cables also can be found in the convoy lorry configuration. Figures 5 and 6 show the nominal stress and stress ranges and in the stay cable due to the convoy lorry configuration.

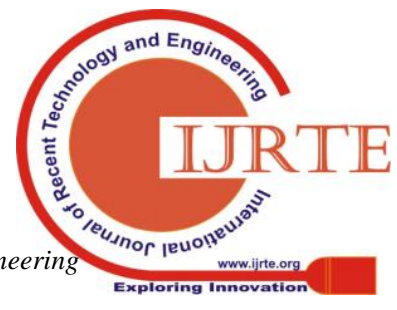






Fig 2. Plot function of applied force in stay cable LS01

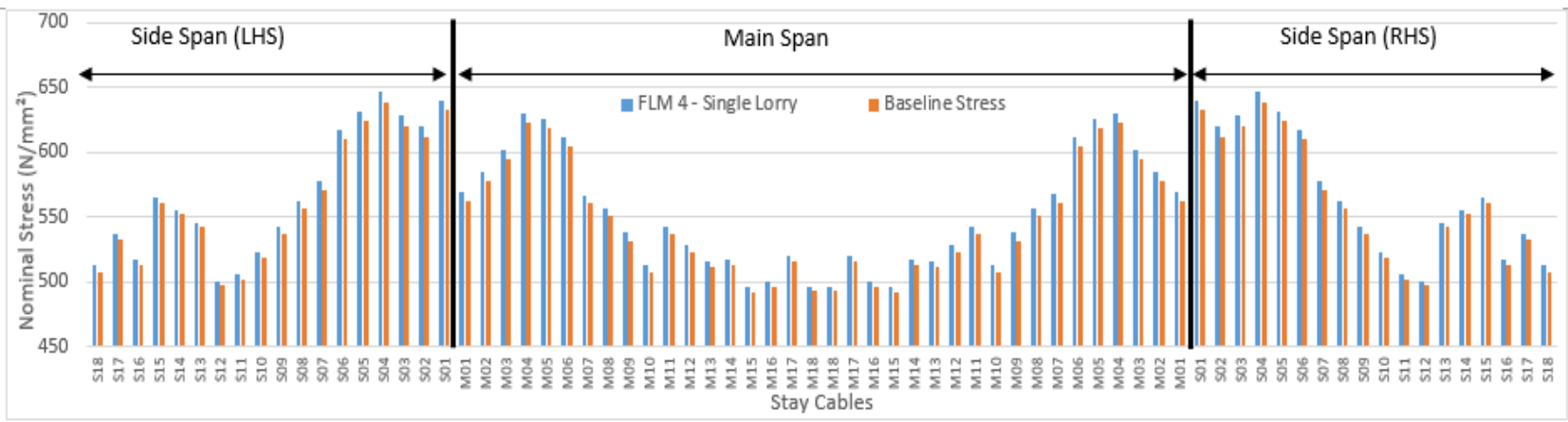

Fig 3. Nominal stress in stay cables due to single lorry configuration

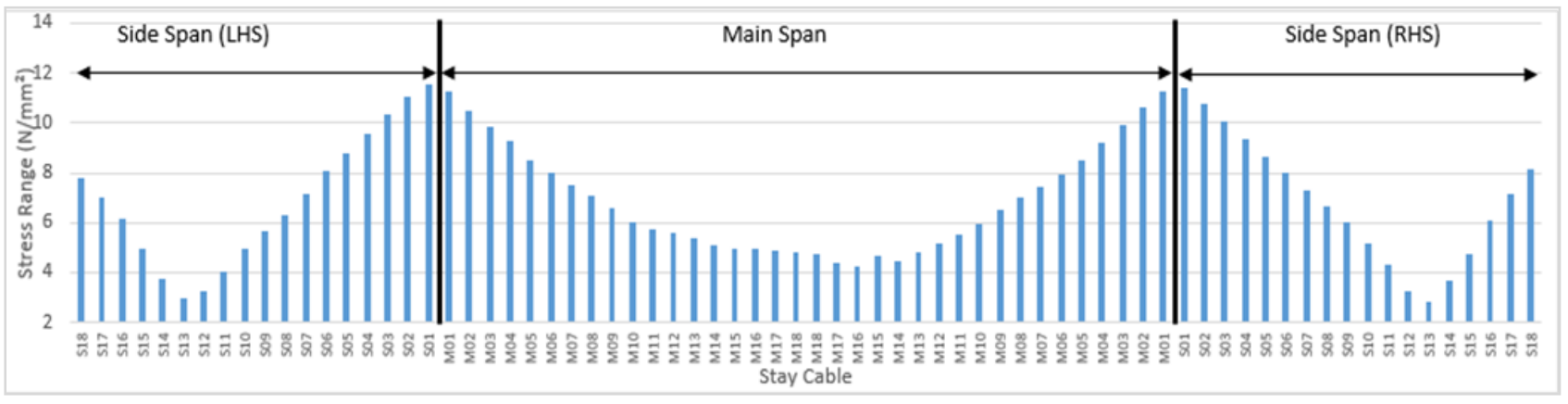

Fig 4. Stress ranges in stay cables due to single lorry configuration

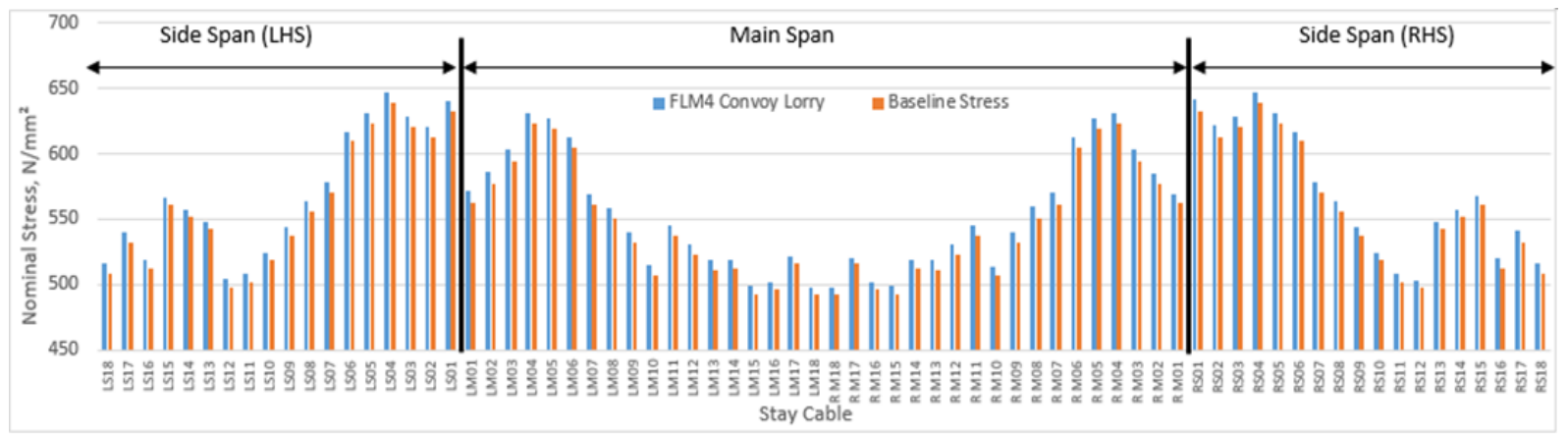

Fig 5. Nominal stress in stay cables due to the convoy lorry configuration

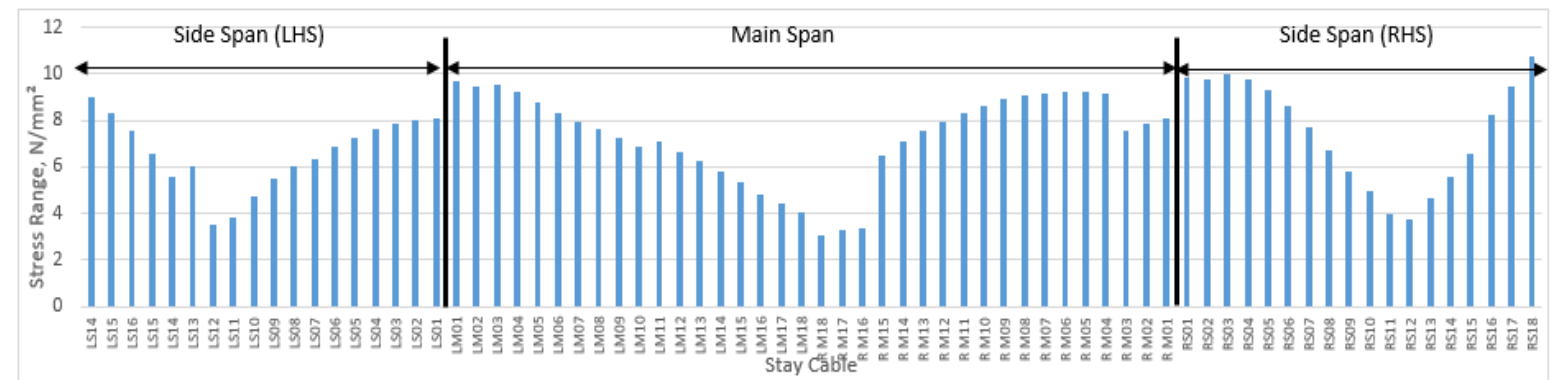

Fig 6. Stress ranges in stay cables due to the convoy lorry configuration

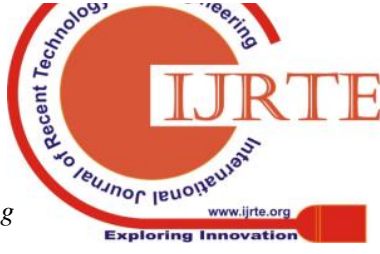




\section{B. Influence by Ground Motion}

The presence of seismic excitation shown in Fig. 7 shows that the round motion exhibits cyclic load that also has a similar effect on the cables as moving traffic. Thus, by using the earthquake events occurring at Kocaeli, Denali and San Simeon, the stress ranges occurring in the stay cables is shown in Fig. 8.
The Denali earthquake has a higher impact on the stay cables compared to the Kocaeli earthquake because the seismic magnitude originating from Denali is higher. Thereby, Fig. 9 shows the variation of stress ranges in stay cables due to moving load and seismic excitation from the Denali earthquake.

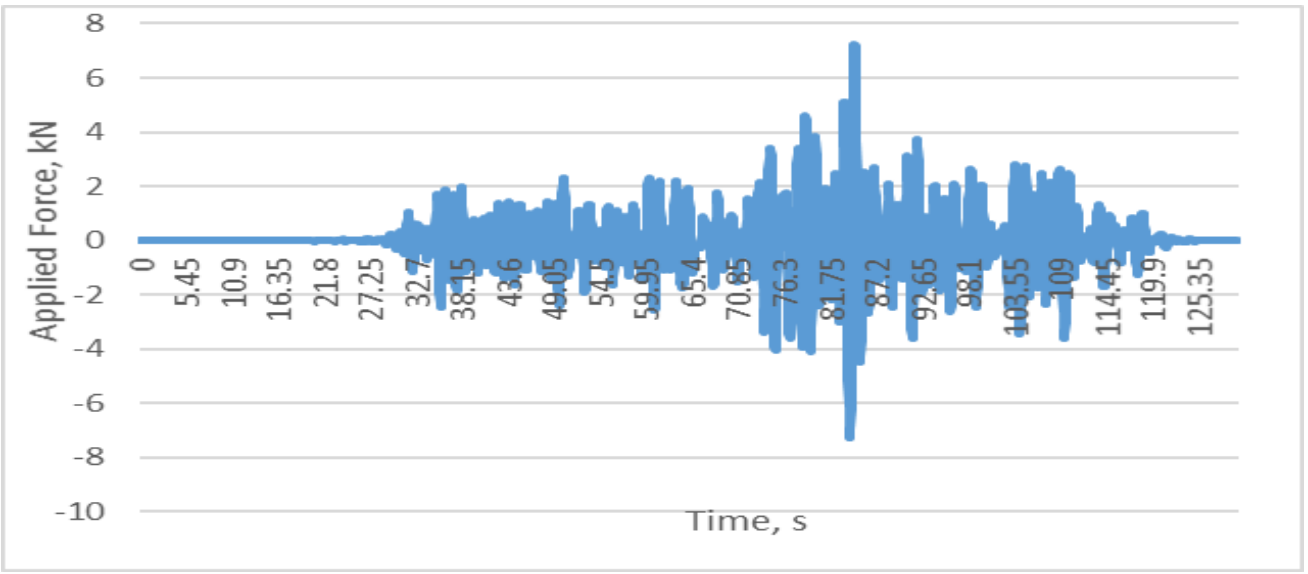

Fig 7. Variation of applied force on stay cable due to the ground motion

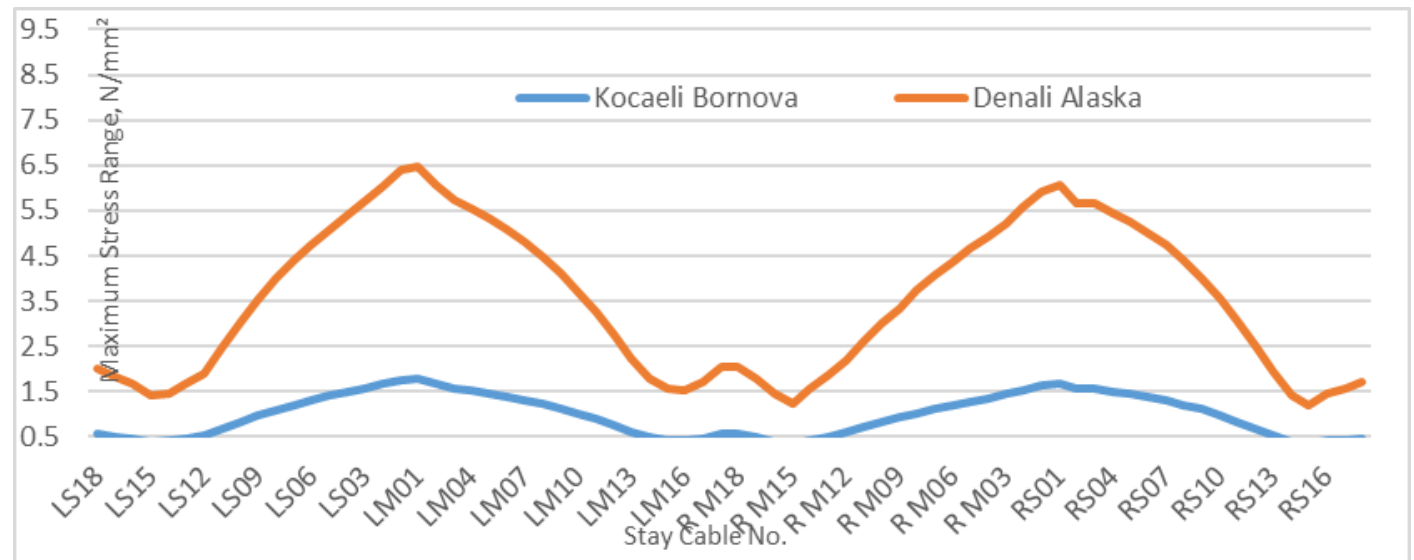

Fig 8. Variation of maximum stress ranges in stay cables due to different applied ground motion

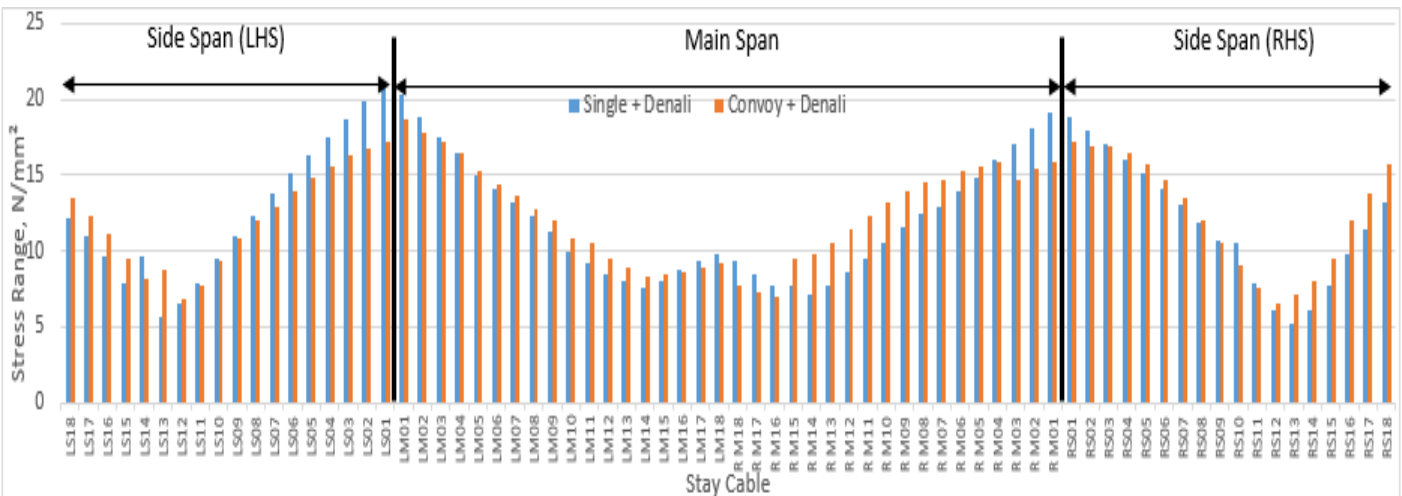

Fig. 9. Variation of stress ranges in stay cables with the combination of moving load and ground motion 


\section{CONCLUSIONS}

The fatigue phenomena may be a jeopardizing condition for bridges especially for long-span bridges. Not only are these structures exposed to moving loads but the exposure to seismic excitation due to earthquakes could expedite the fatigue damage on the bridge. Not many researcher concentrate on the tremor effect on the bridges that can expose bridge structures to fatigue damage. Thus, this study indicates that the tremor of the ground motion could affect the stress range in the stay cables. Plus, with the combination of the two events, the fatigue damage at the critical details such as the cable connection details can be detrimental. However, a detail analysis should be performed in order to gain more information on fatigue damage expectation especially at the critical areas such as at the welded cables deck connection. Therefore, the maintenance schedule for the bridges that encounter both of these two events can be proposed in order to ensure the integrity of the bridge structure.

\section{ACKNOWLEDGMENT}

Author thanks for the sponsor and financial support from the Research Grant of Universiti Malaysia Pahang RDU 1703202 title Analysis of Fatigue Life of Steel Bridge.

\section{REFERENCES}

1. BSI (2003) BS EN 1991-2 part 2: Traffic Load on Bridges. London: British Standard Institution.

2. BSI (2003) NA to BS EN 1991-2 part 2: Traffic Load on Bridges. London: British Standard Institution.

3. Casado, A. C. (2011). Seismic Behaviour of Cable-Stayed Bridges: Design, Analysis and Seismic Devices. In Department of Continuum Mechanics and Theory of Structures, Universidad Politecnica de Madrid, Madrid.

4. Gabler, M. (2015) ). Time for Action. Bridge. Design \& Engineering, (80), 88-89.

5. Hobbs, R. E. \& Ghavami, K. (1982). The Fatigue of Structural Wire Strands. International Journal of Fatigue, 4(2), 69-72

6. Hou Man, L.B., Peng Yun Dong, Chang Chung Man (2018). Design of Main Bridge of Second Penang Bridge in Malaysia. International Journal of Transportation Engineering and Technology, 4(2), 65-42

7. N.A. Muhamad Khairussaleh (2016). Fatigue of Cable Anchorages on a Cable-Stayed Bridges (Ph.D Thesis). University of Surrey.

8. N.A. Muhamad Khairussaleh, G.A.R. Parke, B. Imam (2015). Fatigue Analysis of Cable Anchorages on Cable Stayed-Bridges, Multi-Span Large Bridges (Porto, Portugal) Conference.

9. Shrestha, B. (2014). Seismic response of long-span cable-stayed bridge to near-fault vertical ground motions. KSCE Journal of Civil Engineering, 19(1), 180-187

10. Yan Li, Dagang Lv, Hongfei Sheng (2010). Fatigue Reliability of Stay Cables of Cable-stayed bridge under combined loads of Stochastic Traffic and Wind. Key Engineering Materials, 456(2011), 33-45

11. Timothy D. Ancheta, R.B.D. Jonathan P. Stewart, Emel Seyhan, Walter J. Silva, Brian S.J. Chiou, Katie E. Wooddell, Robert W. Graves, Albert R. Kottke, David M. Boore, Tadahiro Kishida, and Jennifer L. Donahue (2013). PEER NGA-West2 Database. Pacific Earthquake Engineering Research Center, University of California, Berkeley.

12. Russel, H. (2016). Rapid Respond. Bridge. Design \& Engineering, (82), 82-84 